\title{
Screening of Oropharyngeal Dysphagia in Patients with Diabetes Mellitus in El-Demerdash Hospital
}

\author{
MARWA M. SALEH, M.D.*; MERAM M. BEKHET, M.D.**; MONA S. KHODEIR, M.D.* and \\ DONIA A. ZAKARIA, M.Sc.*
}

The Departments of Phoniatrics* and Endocrinology**, Faculty of Medicine, Ain Shams University

\begin{abstract}
Background: Diabetes mellitus is a systemic endocrinal disease that results either from deficiency of insulin hormone (type 1) or from insulin resistance or both (type 2). Literature is scarce related to dysphagia with diabetes. This complaint is expressed by some patients and needs to be explored. AEAT-10 is a questionnaire that explores the presence of dysphagia symptoms among patients.

Aim: The aim of this work is to screen Egyptian diabetic patients (type 1 and type 2) in El-Demerdash Hospital for oropharyngeal dysphagia using the validated Arabic version of Eating Assessment Tool (A-EAT-10) questionnaire to explore the degree of such symptom among them.

Study Design: This was a cross-sectional study conducted to screen the diabetic patients (of both type 1 and type 2) in El-Demerdash Hospital for oropharyngeal dysphagia.

Patients and Methods: 200 Egyptian adult diabetic patients, aged $18 \mathrm{y} .1 \mathrm{~m} .1 \mathrm{~d}-59 \mathrm{y} .12 \mathrm{~m} .31 \mathrm{~d}$, were included in this study. The participants were selected upon certain inclusion and exclusion criteria. The inclusion criteria were diabetic patients of type 1 and/or type 2 . The exclusion criteria were any past or present history of disorders that might cause oropharyngeal dysphagia. Patients were asked to complete the Arabic version of the Eating Assessment Tool-10 (A-EAT10) questionnaire. It is formed of 10 questions, and used to detect the presence of dysphagia complaints among patients and how it affects them.
\end{abstract}

Results: The increase in age and having a female gender were considered of high risk for dysphagia among diabetic patients participating in this study. The commonest symptom among diabetic patients who complained from dysphagia was "I cough when I eat". There is no relation between the type or duration of diabetes mellitus and the presence of oropharyngeal dysphagia.

Conclusion: The present study showed that diabetic patients may encounter swallowing problems. The A-EAT 10 is an easy method that can be used for screening of swallowing difficulty.

Correspondence to: Dr. Marwa M. Saleh, E-Mail: marwa.saleh@.gmail.com
Key Words: Oropharyngeal dysphagia - Diabetes mellitus A-EAT-10.

\section{Introduction}

DYSPHAGIA is the medical term that is used to describe the difficulty of swallowing and the feeling of difficulty in passage of solids or semisolids or liquids from the mouth to the stomach [1-2].

Dysphagia is not a disease, but rather a symptom that results from an underlying etiology or cause [3] . Dysphagia is classified in the clinical setting according to the extent of oral, pharyngeal or esophageal phase deficits into oropharyngeal dysphagia and esophageal dysphagia.

Oropharyngeal dysphagia describes the difficulty to start a swallow in one of its 3 phases; the oral preparatory, oral voluntary and the pharyngeal phases. This may cause food to enter the larynx and lead to choking, coughing, or even aspiration pneumonia. This is typically felt in the region of the back of the throat. While, esophageal dysphagia describes the feeling of food being stuck in neck or chest and this occurs with diseases that involve the esophagus [4].

There are systemic diseases that may cause dysphagia such as [5]:

- Connective tissue diseases such as scleroderma and systemic lupus erythematosus.

- Infectious diseases such as Chagas' disease.

- Inflammatory diseases such as sarcoidosis.

- Endocrinal diseases such as diabetes mellitus.

Dysphagia can have a huge impact on different aspects of a patient's life and is associated with increased morbidity and mortality, and may lead 
to a variety of clinical complications including dehydration, malnutrition and aspiration pneumonia [6]. Although, there are many tools that developed for early detection of dysphagia in the clinical practice, few tools have been developed to assess the patient's perception of his/her dysphagia-related problems in terms of quality of life, emotional and psychosocial effects. Some of these questionnaires are:

- Eating Assessment Tool (EAT-10) is a tool used to measure the swallowing problems. It is also validated in the Arabic language by Farahat and Mosallem [7] and called the validated Arabic version of Eating Assessment Tool (A-EAT-10) for Arab speaking patients with oropharyngeal dysphagia [7].

- The swallowing related quality of life (SWALQOL): was developed by McHorney et al., [8] as a patient-based dysphagia-specific tool to evaluate the impact of swallowing problems on the quality of life in patients with dysphagia.

- M.D. Anderson Dysphagia Inventory (MDADI) was the first validated questionnaire that was designed specifically to assess the effect of dysphagia on quality of life of patients with head/neck cancer [9].

- Dysphagia Handicap Index (DHI) is a validated and standardized English questionnaire that describes the handicapping effect of dysphagia on emotional, functional, and physical aspects of individual's lives [10].

Diabetes mellitus is a systemic endocrinal disease that results either from deficiency of insulin hormone (type 1) or from insulin resistance or both (type 2) [11]. Dysphagia could be a complication of diabetes mellitus and it is observed that all phases of swallowing are affected in diabetes mellitus especially the oropharyngeal phase. Although, the pathophysiology of the oropharyngeal dysphagia in diabetics is still not completely clear, the autonomic neuropathy associated with long term hyperglycemia is claimed to be the cause [12]

Restivo et al., [12] reported that oropharyngeal dysphagia in DM may occur due to impaired coordination between the Inferior Constrictor (IC) muscle and the Cricopharyngeus (CP) muscle of the Upper Esophageal Sphincter (UES) with hyperactivity of the Cricopharyngeus $(\mathrm{CP})$ muscle during the swallowing process.

Questions arise about oropharyngeal dysphagia in diabetes; its prevalence, whether it is related more to diabetes type 1 or type 2 , or duration of diabetes. Literature is scared related to dysphagia with diabetes; however, this complaint is expressed by some patients and needs to be explored.

Aim:

The aim of this work is to screen Egyptian diabetic patients (type 1 and type 2) in El-Demerdash Hospital for oropharyngeal dysphagia using the validated Arabic version of Eating Assessment Tool (A-EAT-10) questionnaire to explore the degree of such symptom among them.

\section{Patients and Methods}

200 Egyptian adult diabetic patients were included in this study. A convenience sample from diabetes mellitus clinic in El-Demerdash Hospital was used to select the participants upon the following inclusion and exclusion criteria during 2016 and 2017.

\section{Inclusion criteria:}

Individuals were eligible for inclusion in this study if they met the following criteria:

1- Patients aged 18y.1m.1d-59y.12m.31d.

2- Patients having diabetes mellitus type 1 and/or diabetes mellitus type 2 .

\section{Exclusion criteria:}

Patients with any past or present history of one of the following disorders that might cause oropharyngeal dysphagia were excluded:

1- Thyroid disorders: Enlargement, inflammation and tumors.

2- Previous brain strokes.

3- Head and neck trauma, cancer or radiation.

4- A systemic disease that might cause dysphagia.

The inclusion and exclusive criteria were determined by the medical history taken from the patients before answering the questionnaire.

A brief medical history was taken firstly prior the questionnaire upon which patients were selected; this involved the following:

Personal history: Patient's name (optional), gender, age, telephone number (optional).

1- History about his/her diabetes: Type of diabetes mellitus (1 or 2), age of onset of the diabetes symptoms, mode of therapy (oral hypoglycemic drugs pills/insulin/oral hypoglycemic drugs pills then shifted to insulin). 
2- Direct questions to exclude any past or present history of the following disorders that might cause oropharyngeal dysphagia:

- Do/Did you suffer from any thyroid diseases (enlargement, inflammation or tumors)? (Y/N).

- Did you suffer from brain strokes? (Y/N).

- Did you suffer from head and/or neck traumas? $(\mathrm{Y} / \mathrm{N})$

- Did you suffer from head and/or neck tumors? $(\mathrm{Y} / \mathrm{N})$

- Do/Did you receive radiotherapy on the head and/or the neck regions? (Y/N).

- Do/Did you suffer from any other disorders? $(\mathrm{Y} / \mathrm{N})$, mention them if the answer is Yes.

The selected patients were given a copy of the validated Arabic version of Eating Assessment Tool (A-EAT-10) to answer its questions. A-EAT10 questionnaire is made up of 10 statements. It used a paper and a pen format and asked participants to respond to each statement by giving a score from 0 to $4(0=$ never, $1=$ rarely, $2=$ sometimes, $2=$ usually and $4=$ always). For the illiterate patients, the phoniatrician read the statements to them and checked their answers.

\section{Scoring of the A-EAT-10 questionnaire:}

A patient with A-EAT-10 score equal to and/or more than 3 is considered dysphagic while patients with score of 2 or less are considered non-dysphagic and may need to be assessed by further tools according to the cut-off value set by Belafsky et al., [13] on a scale from $0-40$.

\section{Data management and analysis:}

The data collected was coded and introduced to a Personal Computer (P.C.) (IBM Corp. Released 2011). The data was analyzed with the program (IBM SPSS) statistical package for social science under windows Version 20.0. Armonk, NY: IBM Corp. Data was presented and suitable analysis was done according to the type of data obtained for each parameter as follows.

\section{The statistical tests used are:}

I- Descriptive statistics:

- Mean, Standard Deviation ( \pm SD) and range for parametric numerical data, while median and Interquartile Range (IQR) for non-parametric numerical data.

- Frequency and percentage of non-numerical data.

\section{II- Analytical statistics:}

- Student $t$-test was used to compare and assess the statistical significance of difference between the dysphagic and non-dysphagic patients involved in this study as regard the type and the duration of diabetes mellitus.

- Mann Whitney test (U-test) was used to compare and assess the statistical significance of difference between the score of the A-EAT-10 questionnaire and the selected patients as regard their gender and the type of diabetes mellitus.

- Chi-Square test was used to determine if there is a significant relationship between the dysphagic and non dysphagic patients involved in this study as regard their ages and gender.

- Multivariate logistic regression was used to explain the relationship between dysphagia and the selected diabetic patients as regard their ages, genders, type and the duration of the diabetes mellitus for the participated patients.

- Multivariate linear regression was used to model the relationship and fit a linear equation between the score of the A-EAT-10 questionnaire and the age, gender, type and the duration of the diabetes mellitus for the participated patients.

\section{Results}

Statistical distribution of the patients who participated in this study:

The mean age of the patients who participated in this study was $39.2 \pm 12.3$, with females representing $66.5 \%$ of the participant patients. $59 \%$ of the participating patients had diabetes mellitus type I, with mean duration of diabetes mellitus of $12.6( \pm 8.7)$ years. Table (1) shows the personal and medical data of the patients participating in this study.

Results of the Arabic version of the Eating Assessment Tool (A-EAT-10) questionnaire:

Table (2) shows the mean score of A-EAT-10 was $1.9( \pm 4.84)$, with a median of zero according to the application of the A-EAT-10 questionnaire. Patients participating in this study were classified into dysphagic and non-dysphagic patients. Table (3) shows that 165 patients $(82.5 \%)$ were nondysphagic, with score less than 3 and 35 patients $(17.5 \%)$ were dysphagic, with score equal to or more than 3 according to the cut-off value set by Belafsky et al., [13] on a scale from 0-40. Table (4) shows the distribution of symptoms among the diabetic patients complaining from dysphagia according to the A-EAT-10 questionnaire. It revealed 
that the most frequent complaint among the diabetic patients who complained from dysphagia according to the A-EAT-10 questionnaire was "I cough when I eat" ( $80 \%$ of dysphagic patients).

Table (1): Mean age, age range, gender, type of the diabetes mellitus, mean duration of diabetes mellitus and the diabetes mellitus duration range of the patients participating in this study.

\begin{tabular}{ll}
\hline Age mean $( \pm \mathrm{SD})$ & $39.28( \pm 12.35)$ \\
Age range (min.-max.) & $18.00-59.00$ \\
Gender: & \\
$\quad$ No. of males (\%) & $67(33.5 \%)$ \\
$\quad$ No. of females (\%) & $133(66.5 \%)$ \\
Type of the diabetes mellitus: & \\
$\quad$ No. of type 1 (\%) & $118(59.0 \%)$ \\
$\quad$ No. of type 2 (\%) & $82(41.0 \%)$ \\
Mean duration of diabetes mellitus ( $\pm \mathrm{SD})$ & $12.67( \pm 8.76)$ \\
Diabetes mellitus duration range (min.-max.) & $1.00-39.00$ \\
\hline
\end{tabular}

Table (2): Results of the A-EAT-10 questionnaire (the mean score of A-EAT-10 questionnaire, standard deviation and the score range (minimum and maximum) given by the study sample patients.

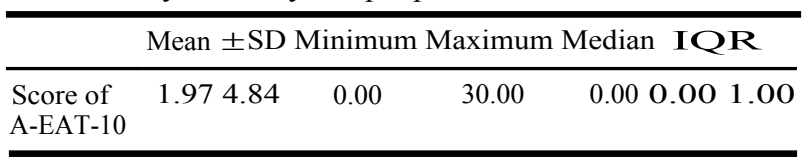

Table (3): The number and the percentage of the dysphagic and non-dysphagic diabetic patients participating in this study).

\begin{tabular}{lc}
\hline & $\begin{array}{c}\text { No. of participated } \\
\text { patients (\%) }\end{array}$ \\
\hline $\begin{array}{l}\text { Non- dysphagic (A-EAT-10 score }<3) \\
\text { Dysphagic (A-EAT-10 score } \geq 3)\end{array}$ & $165(82.5 \%)$ \\
\hline
\end{tabular}

Table (4): Distribution of symptoms among the diabetic patients complaining from dysphagia according to the A-EAT-10 questionnaire.

\begin{tabular}{ccc}
\hline Symptoms & $\begin{array}{c}\text { No of dysphagic } \\
\text { patients who } \\
\text { complained of } \\
\text { this symptom }\end{array}$ & $\begin{array}{c}\text { Percentage of } \\
\text { dysphagic patients } \\
\text { who complained } \\
\text { of this symptom }\end{array}$ \\
\hline 12 & $34.3 \%$ \\
12 & $34.3 \%$ \\
15 & $42.3 \%$ \\
20 & $57.1 \%$ \\
20 & $57.1 \%$ \\
22 & $62.8 \%$ \\
20 & $57.1 \%$ \\
23 & $65.7 \%$ \\
28 & $80 \%$ \\
22 & $62.8 \%$ \\
\hline
\end{tabular}

Table (5) shows that females were found to have a higher mean score of the A-EAT-10 questionnaire compared to males and this difference is statistically significant. There was no relation between the type of diabetes mellitus and the presence of symptoms of oropharyngeal dysphagia as there is no significant difference between the mean score of the A-EAT-10 questionnaire between the patients with diabetes mellitus type 1 and patients with diabetes mellitus type 2 .

Table (5): Relation between the mean score of the A-EAT-10 questionnaire and the gender and type of diabetes mellitus of the participating patients (using Mann Whitney test).

\begin{tabular}{|c|c|c|c|c|}
\hline & \multicolumn{2}{|c|}{$\begin{array}{c}\text { Score of A-EAT-10 } \\
\text { questionnaire }\end{array}$} & \multirow{2}{*}{$\begin{array}{c}p- \\
\text { value }\end{array}$} & \multirow{2}{*}{ Sig. } \\
\hline & $\begin{array}{l}\text { Mean } \\
( \pm \text { SD })\end{array}$ & $\begin{array}{c}\text { Median } \\
\text { (IQR) }\end{array}$ & & \\
\hline \multicolumn{5}{|l|}{ Gender: } \\
\hline Males & $0.70( \pm 2.35)$ & $0(0-0)$ & 0.012 & S \\
\hline Females & $2.60( \pm 5.60)$ & $0(0-2)$ & & \\
\hline \multicolumn{5}{|c|}{ Type of diabetes mellitus: } \\
\hline Type 1 & $1.64( \pm 4.71)$ & $0(0-0)$ & 0.136 & NS \\
\hline Type 2 & $2.43( \pm 5.01)$ & $0(0-2)$ & & \\
\hline
\end{tabular}

Table (6): Comparison between dysphagic and non-dysphagic patients as the mean age and gender (using chisquare tests) and mean duration and type of the diabetes mellitus (using student $t$-test).

\begin{tabular}{ccc}
$\begin{array}{c}\text { Non- } \\
\text { dysphagic }\end{array}$ & Dysphagic & $\begin{array}{c}p \text { - } \\
\text { value Sig. }\end{array}$ \\
\hline
\end{tabular}

- Age mean $( \pm \mathrm{SD}) \quad 38.36( \pm 12.55) \quad 43.63( \pm 10.47) 0.012 \mathrm{~S}$

- Gender:

No. of males (\%) $62 \quad(92.5 \%) \quad 5 \quad(7.5 \%) \quad 0.008$ HS

No. of females (\%) $103(77.4 \%) \quad 30(22.6 \%)$

- Type of diabetes

mellitus:

Type 1 (no. \%) $102(86.4 \%) \quad 16(13.6 \%) \quad 0.578$ NS

Type 2 (no. \%) $63 \quad(76.8 \%) \quad 19(23.2 \%)$

$\begin{array}{llll}\text { - Mean duration of } & 12.84( \pm 8.65) & 11.94( \pm 9.22) & 0.584 \text { NS }\end{array}$

diabetes mellitus $( \pm \mathrm{SD})$

$p>0.05$ : Non-Significant (NS)

$p<0.05$ : Significant (S)

$p<0.01$ : Highly Significant (HS).

\section{Table (6) revealed that:}

1- Patients with higher ages were complaining more from dysphagia symptoms. This is indicated from the high mean age of the dysphagic patients (43.63 \pm 10.47$)$ years compared with the mean age of the non-dysphagic patients (38.36 \pm $12.55)$ years, and this difference was statistically significant. 
2- $22.6 \%$ of the female patients participating in this study complained from dysphagia symptoms compared to only $7.5 \%$ of the participating male patients who had dysphagia and this difference was statistically highly significant.

3- The female diabetic patients complained more frequently from dysphagia symptoms compared to the male diabetic patients, as $30(85.7 \%)$ patients out of the 35 dysphagic diabetic patients were females.

4- $23.2 \%$ of patients with diabetes mellitus type 2 had dysphagia symptoms compared to $13.6 \%$ of patients with diabetes mellitus type 1 who had dysphagia and this difference was statistically of no significance.

5- Type of diabetes mellitus did not relate to the dysphagia symptoms as $45.7 \%$ of patients with dysphagia had diabetes mellitus type 1 , while $54.3 \%$ of them had diabetes mellitus type 2 .

6- There was no statistically significant difference between the dysphagic and non-dysphagic patients as regard the mean duration of the diabetes mellitus.

Studying the risk factors for dysphagia among diabetic patients participating in this study:

Table (7) shows multivariate logistic regression that was used to explain the relationship between dysphagia and the selected diabetic patients as regard their ages, gender, type of diabetes mellitus and the duration of the diabetes mellitus to establish the risk factors for dysphagia among diabetic patients.

After adjusting all the variables, it was shown that the age and gender of the patients were the risk factors for occurrence of dysphagia among diabetic patients who participated in this study. The increase in the age was associated with a higher risk for dysphagia (Odds ratio $=1.04$, confidence interval=1.007-1.076, $p<0.05)$. Also, being a female presents a higher risk for developing dysphagia compared to males (odds ratio $=4.04$, confidence interval=1.4-11.1, $p<0.01)$.

Studying factors affecting the score of the AEAT-10 questionnaire among diabetic patients participating in this study:

Table (8) shows multivariate linear regression that was used to model the relationship and fit a linear equation between the score of the A-EAT10 questionnaire and the age, gender, duration and type of diabetes mellitus of the patients included in this study.
After adjusting all variables, it was shown that age and sex were the independent factors affecting EAT score among diabetic patients, with patients with higher age having higher EAT score, (regression coefficient $=0.056$, confidence interval $=0.003$ $0.11, p<0.05)$ and with female having a higher score compared to males (regression coefficient $=$ 1.9 , confidence interval $=0.5-3.3, p<0.01$ ).

Table (7): Multivariate logistic regression studying the risk factors for dysphagia among the diabetic patients participated in this study.

\begin{tabular}{|c|c|c|c|c|c|}
\hline \multirow[b]{2}{*}{ - Age. } & \multirow{2}{*}{$\begin{array}{c}\begin{array}{c}\text { Odd } \\
\text { Ratios } \\
(\mathrm{OR})\end{array} \\
1.041\end{array}$} & \multirow{2}{*}{$\begin{array}{c}\begin{array}{c}p- \\
\text { value }\end{array} \\
0.019\end{array}$} & \multirow{2}{*}{$\begin{array}{c}\begin{array}{c}\text { Signi- } \\
\text { ficance }\end{array} \\
S\end{array}$} & \multicolumn{2}{|c|}{$\begin{array}{c}95 \% \\
\text { Confidence Interval } \\
\text { (CI) for OR }\end{array}$} \\
\hline & & & & 1.007 & 1.076 \\
\hline $\begin{array}{l}\text { - Duration of diabetes } \\
\text { mellitus. }\end{array}$ & 0.983 & 0.469 & NS & 0.939 & 1.030 \\
\hline $\begin{array}{l}\text { - Female (reference } \\
\text { male). }\end{array}$ & 3.834 & 0.009 & HS & 1.395 & 10.538 \\
\hline $\begin{array}{l}\text { - Diabetes mellitus } \\
\text { Type } 2 \text { (reference } \\
\text { diabetes mellitus } \\
\text { Type } 1 \text { ). }\end{array}$ & 1.344 & 0.528 & NS & 0.536 & 3.368 \\
\hline
\end{tabular}

Table (8): Multivariate linear regression studying factors affecting the score of the A-EAT-10 questionnaire among diabetic patients participating in this study.

\begin{tabular}{|c|c|c|c|c|c|}
\hline \multirow[b]{2}{*}{ - Age. } & \multirow{2}{*}{$\begin{array}{c}\begin{array}{r}\text { Regression } \\
\text { coefficient }\end{array} \\
0.056\end{array}$} & \multirow{2}{*}{$\begin{array}{c}\begin{array}{c}p- \\
\text { value }\end{array} \\
0.040\end{array}$} & $\begin{array}{l}\text { Signi- } \\
\text { ficance }\end{array}$ & \multicolumn{2}{|c|}{$\begin{array}{c}95 \% \text { of } \\
\text { Confidence Interva } \\
(\mathrm{CI}) \text { for } \\
\text { Regression } \\
\text { coefficient }\end{array}$} \\
\hline & & & $\mathrm{s}$ & 0.003 & 0.110 \\
\hline - Disease duration. & -0.025 & 0.537 & NS & -0.106 & 0.055 \\
\hline $\begin{array}{l}\text { - Female (reference } \\
\text { male). }\end{array}$ & 1.922 & 0.007 & HS & 0.525 & 3.319 \\
\hline $\begin{array}{l}\text { - Diabetes mellitus } \\
\text { Type } 2 \text { (reference } \\
\text { diabetes Mellitus } \\
\text { Type } 1 \text { ). }\end{array}$ & 0.099 & 0.909 & NS & -1.612 & 1.811 \\
\hline
\end{tabular}

\section{Discussion}

This study presents a screening of the oropharyngeal dysphagia in adult young and middle aged Egyptian diabetic patients with either type 1 and/or type 2 diabetes mellitus, in the age range of $18 \mathrm{y} .1 \mathrm{~m} .1 \mathrm{~d}-59 \mathrm{y} .12 \mathrm{~m} .31 \mathrm{~d}$. The selected patients have no associated disorders that might cause oropharyngeal dysphagia.

Among the different tools that screen symptoms of oropharyngeal dysphagia, the A-EAT-10 was chosen to be used in this study as being a validated, 
reliable, rapidly administered and easily scored dysphagia screening tool that can be applied in each patient's visit and it can generally assess symptom severity, quality of life, and treatment efficacy. It is worded in a manner that makes it simple and it is not time consuming, it takes only 2 minutes to be completed and needs no training. There are no subscales to address and no formulas required to calculate a raw score. The clinician only needs to add up the numbers. Farahat and Mosallem [7] reported that the A-EAT-10 is considered a screening tool for patients with oropharyngeal dysphagia and it can differentiate healthy population from patients with dysphagia so this serves our aim of the study.

There are only two available valid and reliable questionnaires present in the Arabic language to screen self perception of dysphagia; the A-EAT10 and the A-DHI (dysphagia handicap index). The A-EAT-10 was chosen as it maintained its validity and reliability as a self-administered screening tool for patients with oropharyngeal dysphagia. This questionnaire was easy to administer, easily understood by patients and took only few minutes to complete. On the other hand, the A-DHI is formed of 25 questions mainly used to measure the handicapping effect of dysphagia on the physical, functional and emotional aspects of people's lives.

The results obtained in this study would be addressed concerning 3 main findings:

- The presence of $17.5 \%$ of diabetic patients complaining of dysphagia symptoms.

- The significantly higher number of dysphagia symptoms in female diabetics.

- The significant increase in dysphagia symptoms in diabetics with age.

After the application of the A-EAT-10 questionnaire on 200 adult Egyptian diabetic patients, the obtained results revealed that 165 patients $(82.5 \%)$ were non-dysphagic while, 35 patients $(17.5 \%)$ were dysphagic. Although in literature, dysphagia has been observed in diabetic patients, but its prevalence has never been assessed [12]

In the present study, an A-EAT-10 score of $\geq 3$ was considered abnormal based on the original study by Belafsky et al., [13]. However, two other cut off values were reported in literature. One was by Rofes et al., [14] who suggested that reducing the cutoff value from 3 to 2 increased the test's sensitivity by $5 \%$ without affecting specificity.
On the other hand, Farahat and Mosallem [7] in the Arabic version of the assessment tool yielded an A-EAT-10 score of 5.8 for a control group of 83 asymptomatic individuals. They did not find a reason for their higher mean value. The authors of the present study chose to abide by the cut off value of Belafsky et al., [13] to avoid false negative or false positive results. Further studies using this assessment tool would help to clarify a reliable cut off value.

It should be noted that Belafsky et al., [13] obtained the mean from 100 individuals of normal population with a mean age of $48 \pm 16$ years. The mean EAT-10 score for the normal participants was $0.40 \pm 1.01$. The mean plus $2 \mathrm{SD}$ yielded an upper limit for normal EAT-10 score of 2.41. The authors suggested a score of 3 or above to be abnormal.

Having $17.5 \%$ of diabetic patients above the normal cut off value is to be considered an indication that roughly about one in every six diabetic patients could experience dysphagic symptoms which are just symptoms reflecting swallowing impairment caused by diabetes.

As regards Table (4) in the results, it shows the percentage of dysphagic patients who complained from each symptom, the commonest symptom was "I cough when I eat". This implies aspiration which could correlate with what Restivo et al., [12] mentioned about hyperactivity in the cricopharyngeus leading to aspiration after the swallow. The second most common complaint was "when I swallow, food sticks in my throat" which also implies delayed emptying of the pharynx.

Results of the present study revealed that patients with higher age complained from symptoms of oropharyngeal dysphagia more than those with younger age. This is indicated from the high mean age of the dysphagic patients $(43.63 \pm 10.47)$ years compared with the mean age of the non-dysphagic patients $(38.36 \pm 12.55)$ years, and this difference was statistically significant. These results coincide with Borgstrom et al., [15] who found that older patients presented with more severe pharyngeal dysfunction than did the younger patients. This may be since swallowing physiology becomes more affected with age.

Females were found to have a higher A-EAT10 score in our study. This is indicated from a higher percentage of female patients with dysphagia (22.6\% of the female patients) compared to only $7.5 \%$ of the participated male patients who had dysphagia and this difference was statistically 
significant. No other studies discussed the sex difference.

Results in the present study revealed that there was no statistically significant difference between the dysphagic and non-dysphagic patients as regard the mean duration of the diabetes mellitus. Therefore, there is no relation between the duration of diabetes mellitus and the presence of oropharyngeal dysphagia. This coincides with Borgstrom et al., [15] who concluded that no correlation was reported between the duration of the diabetes and the degree of dysfunction. Borgstrom et al., [15] monitored pharyngeal and oesophageal function using cine and video techniques in 18 diabetic patients with swallowing complaints. Abnormal pharyngeal function was present in 14 patients and abnormal oesophageal function in 10 patients. 8 of these patients had both pharyngeal and oesophageal dysfunction. Cineradiographs were analyzed retrospectively for pharyngeal function. Areas looked at included epiglottic movement, closure of the laryngeal vestibule, pharyngeal constrictor peristalsis, motor function of the pharyngooesophageal segment, including the Crico-pharyngeus muscle, as well as the presence of webs or diverticulae. Results revealed that of the 14 patients with pharyngeal dysfunction, 5 patients had paresis of the pharyngeal constrictors, 4 patients had defective opening of the upper esophageal sphincter, and 7 patients had more than one pharyngeal abnormality.

The present study included 118 patients of type 1 diabetes and 82 patients of type 2 diabetes. Results revealed that $23.2 \%$ of patients with diabetes mellitus Type 2 had dysphagia symptoms compared to $13.6 \%$ of patients with diabetes mellitus type 1 who had dysphagia and this difference was statistically of no significance. Therefore, there was no relation between the type of diabetes mellitus and the presence of oropharyngeal dysphagia.

This contrasted with the study of Boolkin [16] Boolkin [16] designed a study to examine the incidence of dysphagia in a group of 50 diabetic patients and showed a significant relationship between swallowing dysfunction and diabetes predominantly during the pharyngeal and oesophageal phases of the swallow process. Booklin [16] related dysphagia in diabetes mellitus to neuropathy and found that $70.9 \%$ of patients with type 1 diabetes had dysphagia. The type 1 diabetic patients experienced dysphagia in any of the three phases. On the other hand, $44.4 \%$ of patients with type 2 diabetes had dysphagia. Therefore, Booklin [16] concluded that higher incidence of dysphagia occurs within the type 1 diabetic population.

\section{Conclusion and Recommendations:}

The present study showed that diabetic patients may encounter swallowing problems. Thus, diabetic patients (type 1 or type 2 ) should be screened for dysphagia (especially in cases of neuropathy) to deal with dysphagia as soon as possible.

The A-EAT 10 is an easy method that can be used for screening of swallowing difficulty and should be applied as a screening tool for oropharyngeal dysphagia on a larger sample of diabetic patients to estimate the prevalence of dysphagia in diabetics in the community.

The application of the A-EAT 10 should be followed by objective methods in suspected cases as no screening test is $100 \%$ accurate.

\section{References}

1- SMITHARD D.G., SMEETON N.C. and WOLFE C.D.: Long-term outcome after stroke: Does dysphagia matter. Age Ageing Journal, 36 (1): 90-4, 2007.

2- BRADY A.: Managing the patient with dysphagia. Home Healthcare Nurse Journal, 26 (1): 41-6, 2008.

3- JUSTICE L.M.: Communication sciences and disorders: An introduction. New Jersey: Pearson Education, 2006.

4- GYAWALI C.P.: Overview on dysphagia. The American College of gastroenterology. Washington University School of Medicine, St. Louis, MO, 2010.

5- WISE J.L. and MURRAY J.A.: Oral, pharyngeal and esophageal motility disorders in systemic diseases. GI Motility online. 2006; Doi: 10.1038/gimo40.www.nature. c om/gimo/contents/pt 1 /full/gimo40. html.

6- ETGES C.L., SCHEEREN B., GOMES E. and BARBOSA L.D.: Screening tools for dysphagia: A systematic review. Communication Disorders, Audiology and Swallowing Journal, 26 (5): 343-9, 2014.

7- FARAHAT M. and MESALLAM T.A.: Validation and cultural adaptation of the Arabic version of the Eating Assessment Tool (A-EAT-10). Folia Phoniatrica et Logopedica, 67: 231-7, 2015.

8- McHORNEY C.A., BRICKER D.E., KRAMER A.E., ROSENBEK J.C., ROBBINS J., CHIGNELL K.A. and CLARKE C.: The SWAL-QOL outcomes tool for oropharyngeal dysphagia in adults: I. Conceptual foundation and item development. Dysphagia Journal, 15 (3): 115$21,2000$.

9- CHEN A.Y., FRANKOWSKI R., BISHOP-LEONE J., HEBERT T., LEYK S., LEWIN J. and GOEPFERT H.: The Development and validation of a dysphagia-specific quality-of-life questionnaire for patients with Head and Neck Cancer. The M. D. Anderson Dysphagia Inventory. Arch Otolaryngology Head Neck Surgery Journal, 127 (7): 870-6, 2001. 
10- FARAHAT M., MALKI K.H., MESALLAM T.A., BUKHARI M. and ALHARETHY S.: Development of the Arabic version of Dysphagia Handicap Index (ADHI). Folia Phoniatrica et Logopedica Journal, 29: 45967, 2014.

11- DATTANI M.T. and GEVERS E.F.: Endocrinology of fetal development. In: Williams Textbook of Endocrinology, 13 th ed. 2016; Philadelphia: Elsevier, chapter 32.

12- RESTIVO D.A., RAGONA R.M., LAURIA G., SQUATRITO S., GULLO D. and VIGNERI R.: Botulinum toxin treatment for oropharyngeal dysphagia associated with diabetic neuropathy. Diabetes Care Journal, 12: 2650-3, 2006.

13- BELAFSKY P.C., MOUADEB D.A., REES C.J., PRYOR J.C., POSTMA G.N., ALLEN J. and LEONARD R.J.:
Validity and reliability of the Eating Assessment Tool (EAT-10). Annals of Otology, Rhinology and Laryngology Journal, 117 (12): 919-24, 2008.

14- ROFES L., ARREOLA V., MUKHERJEE R. and CLAVE P.: Sensitivity and specificity of the Eating Assessment Tool and the Volume-Viscosity Swallow Test for clinical evaluation of oropharyngeal dysphagia. Neurogastroenterology and Motility Journal, 26: 1256-65, 2014.

15- BORGSTROM P.S., OLSSON R., SUNDKVIST G. and EKBERG O.: Pharyngeal and oesophageal function in patients with diabetes mellitus and swallowing complaints. The British Journal of Radiology, 61: 817-21, 1988.

16- BOOLKIN L.: The incidence of dysphagia in diabetic patients (Doctoral dissertation). Wits Institutional Repository (WIReDSpace), 2016. 


\section{فحص صعوبة البلع الفم بلعومية فى مرضى السكرى الفئ

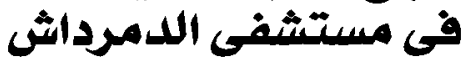

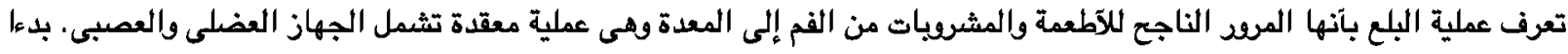

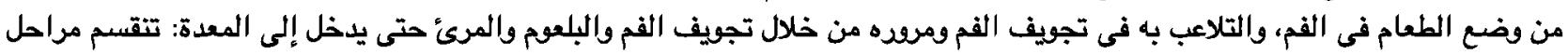

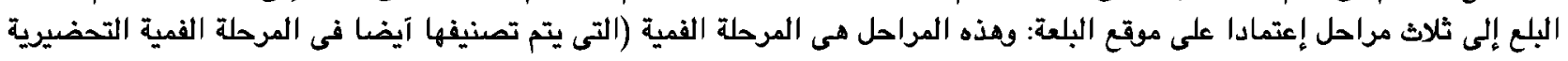

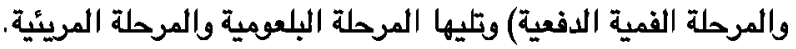

آما عسر البلع فهو صعوية بلع السوائل والمواد الصلبة، والآدوية وحتى اللعاب بدءا من الفم وصولا إلى المعدة عسر البلع هو عرض يتتج

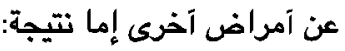
"إختلالات المرحلة الفمية والبلعومية آو ما تعرف بصعية آمرية البلع "الفم-بلعومية. "آو نتيجة إختلالات فى المرحلة المريئية "صعوية البلع المريئى.

هناك آمراض عامة كثيرة تصيب آجهزة الجسم قد تسبب عسر البلع ومنها: آمراض الغدد الصماءكداء السكرى.

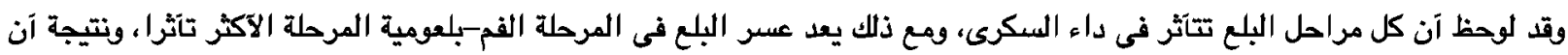

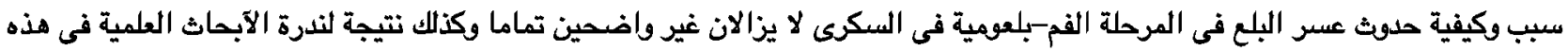

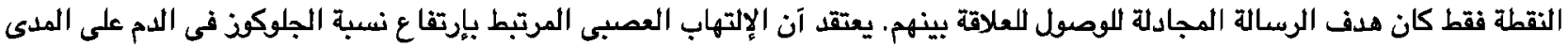

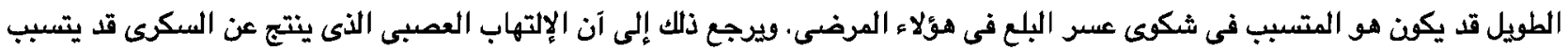

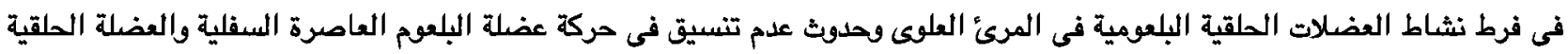
البلعومية.

الهدف من هذا البحث: الهدف من هذا البحث هو عمل لعرض عسر البلع الفم-بلعومى في مرضى السكرى المصريين (من النوع الآهل

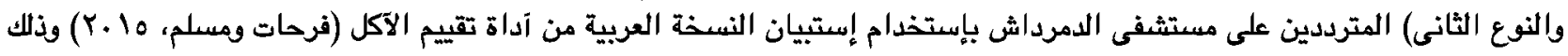
لإكتشاف درجة إنتشار هذا العرض بينهم.

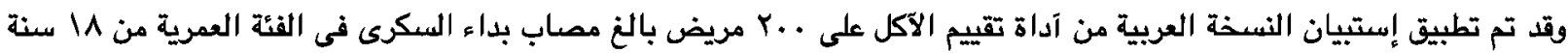

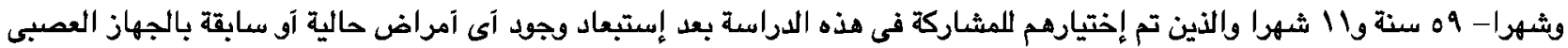

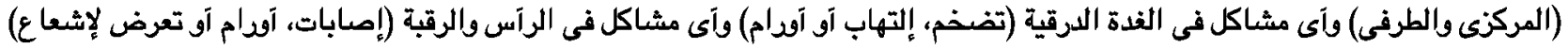
وكذلك آى آمراض عضوية آخرى قد تسبب عرض الفرة عسر البلع الفم بلعقمى. وقد آوضحت نتائج الدراسة آن: - الثكوى الاكثر تكرارا بين مرضيى السكرى الذين لديهم عسر بلع كانت "آصاب بالكحة عندما آكل".

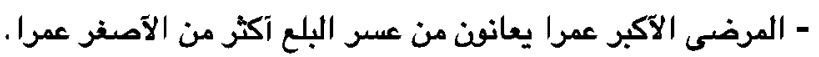
- الإناث أكثر شكوى من عسر البلع من الذكور.

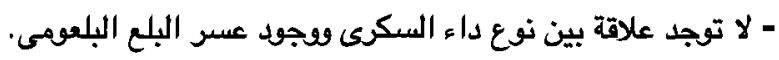

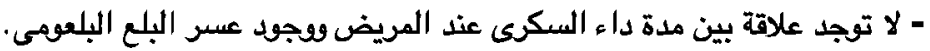

